\title{
BMJ Open Long-term outcomes for Asian patients with X-linked hypophosphataemia: rationale and design of the SUNFLOWER longitudinal, observational cohort study
}

To cite: Kubota T, Fukumoto S, Cheong HI, et al. Longterm outcomes for Asian patients with X-linked hypophosphataemia: rationale and design of the SUNFLOWER longitudinal, observational cohort study. BMJ Open 2020;10:e036367. doi:10.1136/ bmjopen-2019-036367

- Prepublication history and additional material for this paper are available online. To view these files, please visit the journal online (http://dx.doi. org/10.1136/bmjopen-2019036367).

Received 12 December 2019 Revised 30 April 2020 Accepted 03 June 2020

Check for updates

(C) Author(s) (or their employer(s)) 2020. Re-use permitted under CC BY-NC. No commercial re-use. See rights and permissions. Published by BMJ.

For numbered affiliations see end of article.

Correspondence to

Dr Takuo Kubota;

tkubota@ped.med.osaka-u.ac.jp

\section{ABSTRACT}

Introduction X-linked hypophosphataemic rickets/ osteomalacia $(\mathrm{XLH})$ is a chronic, debilitating genetic disease characterised by skeletal abnormalities and growth disorder. The burden of XLH begins in childhood and continues throughout life. Conventional medical therapy with phosphate, active vitamin D and surgery do not address the underlying pathophysiology of the disease. While treatment during childhood may improve bone deformity and growth retardation, a large proportion of adult patients still fail to reach normal stature. Furthermore, adult patients with XLH report comorbidities associated with unresolved childhood disease, as well as newly developed disease-related complications and significantly impaired quality of life (QOL). Despite the multiple negative aspects of XLH, Asian consensus statements for diagnosis and management are lacking.

Methods and analysis The Study of IongitUdinal observatioN For patients with X-Linked hyp0phosphataemic rickets/osteomalacia in collaboration With Asian partnERs study is a Iongitudinal observational cohort study of patients with XLH, designed to determine the medical characteristics and burdens (physical, emotional and financial) of this progressive disease and to evaluate the impact of treatment (including the use of burosumab) on clinical outcomes. The study was initiated in April 2018, and registration will remain open until 30 April 2022. The sample size planned for analyses is 160 patients, consisting of 100 patients in Japan and 60 patients in Korea. Up to 5 years of observation are planned per patient, from enrolment through to April 2023. Prospective and retrospective data will be collected to evaluate variables, including height/growth, rickets severity score, QOL, motor function and biomarkers for phosphate metabolism and bone turnover.

Ethics and dissemination Ethics approval was obtained from the Ethics Committee of Osaka University, the Ethics Committee of Kyowa Kirin Co and by the Ethics Committee of each participating medical institution. Two interim analyses and associated publications are planned using retrospective and enrolment data at year 1 and results at year 3 .

\section{Strengths and limitations of this study}

- The SUNFLOWER (Study of longitUdinal observatioN For patients with X-Linked hypOphosphataemic rickets/osteomalacia in collaboration With Asian partnERs) study was designed to determine the medical characteristics and natural course of X-linked hypophosphataemic rickets/osteomalacia (XLH); to determine the physical, psychological and economic burden of XLH through long-term observation, and to evaluate treatment efficacy and safety.

- Only patients with a confirmed diagnosis of XLH will be included, many of whom are likely to have received at least some treatment for their condition; therefore, examination of the disease process in untreated patients may be limited, depending on data availability.

- Undiagnosed patients with fewer or less severe clinical manifestations may be unaware of their XLH status; thus, although the study has no restrictions on enrolment according to stage or severity, cases with a mild disease phenotype may be poorly represented in the analysis, potentially resulting in a bias towards more severe forms of the disease.

- This study will be conducted in Japanese and Korean patients only, and we cannot exclude the possibility that disease characteristics may vary according to ethnicity, potentially confounding the ability to extrapolate the study data to XLH patient populations in other countries.

- As the largest multicentre cohort of XLH patients evaluated in Asia to date, the SUNFLOWER study will be critical to advancing our knowledge of this debilitating disease, and it is hoped that the data accrued may contribute to future global consensus guidelines for XLH diagnosis and management.

Trial registration numbers NCT03745521;

UMIN000031605.

\section{INTRODUCTION}

X-linked hypophosphataemic rickets/osteomalacia $(\mathrm{XLH})$ is a rare, serious, debilitating, 
chronic genetic disease, with an incidence of approximately 1 in 20000 people. ${ }^{1-3}$ XLH is inherited in an X-linked dominant pattern and results from inactivating mutations of the phosphate-regulating gene with homologies to endopeptidases on the $\mathrm{X}$ chromosome (PHEX) ${ }^{4}$ Impaired function of PHEX protein is believed to cause $\mathrm{XLH}^{5}$ and, to date, $>300$ different PHEX gene mutations have been identified in patients with XLH. ${ }^{6-8} \mathrm{XLH}$ is the most common form of inherited rickets and is characterised by renal phosphate wasting with subsequent hypophosphataemia, impaired bone mineralisation, impaired endochondral ossification in the growth plate and bone deformities. ${ }^{6}{ }^{10}$ Hypophosphataemia occurs in patients with XLH owing to elevated levels of FGF23. ${ }^{611} 12$ However, the exact mechanism by which PHEX dysfunction results in an increase in FGF23 is complex and is not yet fully understood. ${ }^{5613}$

The burden of XLH begins in childhood, with significant levels of pain and impaired physical functioning, and continues throughout life $^{14}$; adults with XLH have comorbidities associated with unresolved childhood disease, as well as newly developed disease-related problems. ${ }^{14} 15$ Skeletal abnormalities (eg, bowing deformities of the legs) and growth disorder commonly appear in late infancy and may result in short stature through adulthood. ${ }^{61016}$ Children with XLH often develop dental problems such as spontaneous dental abscesses. ${ }^{15}$ Adult patients with XLH have increased disability, musculoskeletal pain and risk of active fractures (including pseudofractures), joint abnormality and enthesopathies (eg, spinal ligament ossification), ${ }^{56}$ and they may suffer from hearing impairment and dental problems. ${ }^{17}{ }^{18}$ Furthermore, complications such as craniosynostosis in children and Chiari I malformations in both children and adults have also been reported in XLH patients. ${ }^{19-21}$ However, despite the major impacts of XLH on patient functioning, quality of life (QOL) data in this patient population are scarce. One prospective study in 52 adult patients reported that QOL associated with XLH was worse than that associated with axial spondyloarthritis, a disease with a high functional disability; the presence of musculoskeletal and dental complications in XLH was significantly associated with worse QOL scores. ${ }^{17} \mathrm{~A}$ recent burden of disease survey reported that the clinical manifestations of XLH place a substantial burden on children with the disease and that this burden continues into adulthood, resulting in a lifelong detriment to health. ${ }^{14}$

Long-term outcomes of patients with XLH are dependent on early diagnosis and timely initiation of therapeutic management. ${ }^{22}$ Treatment goals are to reduce bone deformity and increase height in children, relieve pain in adults and improve osteomalacia and healing of active fractures (including pseudofractures). ${ }^{5}$ However, despite treatment with active vitamin $\mathrm{D}$ analogues and phosphate salts, disease manifestations may be insufficiently controlled, ${ }^{17}$ and some patients with XLH may require surgical correction for limb deformity, spinal decompression and joint replacement. ${ }^{18} 2324$ Furthermore, although appropriate conventional pharmacological treatment from childhood can improve growth, it does not result in normalisation of adult height in a large proportion of patients. ${ }^{15}$ Previous observational studies of XLH have evaluated the association between lack of treatment in childhood and an increase in complications in adulthood. ${ }^{25}{ }^{26}$ However, because of the small number of patients in individual studies, owing to the scarcity of XLH, only limited conclusions can be drawn. Furthermore, there is little information on treatment policies among medical institutions and regions/countries. Although a few clinicians' guides have been published ${ }^{51522}$ and a diagnostic flowchart for FGF23-related hypophosphataemic diseases (which includes XLH) was proposed in Japan, ${ }^{27}$ the lack of global consensus guidelines might result in heterogeneous and potentially suboptimal disease management. Recently, a group of European clinicians published clinical practice recommendations for the diagnosis and management of XLH, and claimed that 'knowledge about this condition is unfortunately often restricted to a few specialised centres' ${ }^{28}$ Thus, it is evident that a widespread clinical understanding of XLH is lacking, and additional disease information is needed to inform physicians in this field with the ultimate aim of developing globally accepted guidelines for XLH diagnosis and management.

Owing to the widespread lack of accord regarding the disease course and optimal management techniques in Asia, there is a clear need for observational studies providing clinical information on the changing characteristics of this disease over time. The SUNFLOWER (Study of longitUdinal observatioN For patients with X-Linked hypOphosphataemic rickets/osteomalacia in collaboration With Asian partnERs) study was designed to determine the medical characteristics and natural course of the disease; to determine the physical, psychological and economic burden of XLH through long-term (up to 5 years) observation of patients and to evaluate treatment efficacy and safety in patients with XLH. In addition to the prespecified, observational measurements obtained during the study, retrospective data will also be collected, which will enable us to produce a detailed picture of the XLH disease process across long periods. This study should expand the foundations of our knowledge of the clinical picture across the XLH disease severity spectrum. Assessing which patients need treatment, when to give treatment and what drugs are most appropriate will be the future research questions that will be considered using the data set obtained in this study. It is hoped that the information accrued during this study will contribute significantly to developing a future global consensus guideline for XLH diagnosis and management.

\section{METHODS AND ANALYSIS}

\section{Design and setting}

The SUNFLOWER study is a longitudinal observational cohort study of patients with XLH. The study was initiated in April 2018, and registration will remain open until 30 April 2022. Up to 5 years of observation are planned per patient, from enrolment through to April 2023. The study will initially be conducted in Japan and Korea. However, 


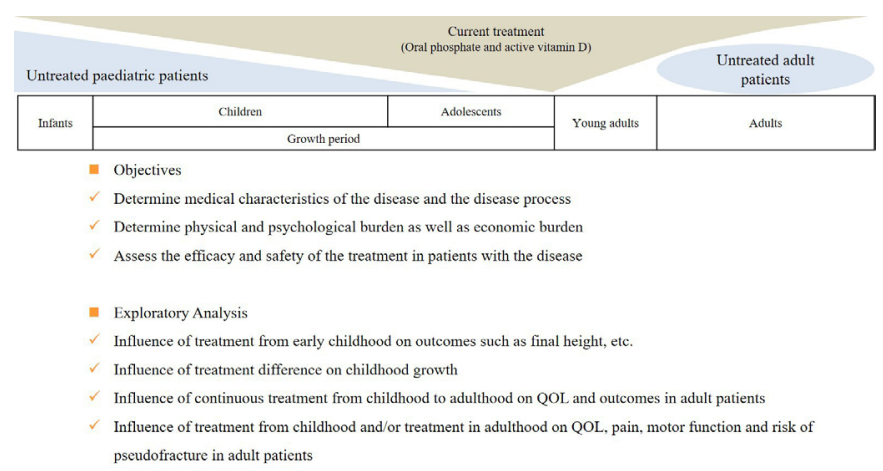

Figure 1 Objectives and exploratory analysis in the longitudinal, observational Study of longitUdinal observatioN For patients with X-Linked hypOphosphataemic rickets/ osteomalacia in collaboration With Asian partnERs study. QOL, quality of life.

additional regions may subsequently be included if it becomes necessary to increase the accrual rate.

\section{Target population and sample size}

All outpatients, including adults and children, with XLH at each study centre, who have given consent (or whose parents/guardians have given consent for patients aged $<20$ years (Japan) or $<19$ years (Korea)) to participate in the study, will be enrolled. In order to collect general data on XLH, no inclusion/exclusion criteria based on the stage or severity of the disease have been established; thus, data from patients with symptoms ranging from mild to severe should be available for analysis.

The sample size planned for analyses is 160 patients, consisting of 100 patients in Japan and 60 patients in Korea. The sample size was determined based on feasibility and the number of potential XLH outpatients that can be enrolled in participating medical institutions. Owing to the lack of evidence from prior research and the scarcity of relevant information, no calculations for sample size or statistical power were conducted.

\section{Inclusion criteria}

The study population will include patients of any age who have been clinically diagnosed with XLH, and who have one or more of the following: a documented PHEX mutation, at least one family member with a documented PHEX mutation or a documented intact FGF23 level $>30 \mathrm{pg} / \mathrm{mL}$ (cut-off value for diagnosing FGF23-related hypophosphataemia ${ }^{29}$; measured by Kainos Laboratories, Tokyo, Japan). Participants must also have a history or current physical signs of rickets/osteomalacia, regardless of treatment history (presence/absence of treatment or type of treatment). The retrospective data will be used to determine a history of osteomalacia based on the definition of osteomalacia stated in the Diagnosis Manual of Rickets and Osteomalacia. ${ }^{30}$

\section{Exclusion criteria}

Study exclusion criteria are participation in another clinical study at the time of informed consent (participation in this study will be allowed after completion of any other relevant clinical study) and presence of any characteristic that may make participation inappropriate or unsafe.

\section{Outcomes}

In figure 1, we describe the objectives of the SUNFLOWER study, the specific clinicopathological areas of interest and the information that will be collected and evaluated. For patients aged $<18$ years, primary study outcome measures are assessments of height, rickets severity score, ${ }^{31}$ QOL and motor function. For patients aged $\geq 18$ years, primary study outcome measures are QOL and motor function assessment.

For patients aged $<18$ years, secondary outcome measures include measurements of growth velocity, lower limb deformity, biomarkers for phosphate metabolism and bone turnover and frequency of active fractures (including pseudofractures). For patients aged $\geq 18$ years, secondary outcome measures include measurement of biomarkers for phosphate metabolism and bone turnover, frequency of active fractures (including pseudofractures), spinal ligament ossification, nephrocalcinosis and renal function. To adequately evaluate a pseudofracture, the participating institution will be requested to provide imaging data, such as radiographs, CT images and MRI, and the registered data will be evaluated by the Central Evaluation Committee consisting of orthopaedic surgeons and radiologists. If a study patient presents a fracture, the attending physician will fill out an evaluation form in which the fracture will be classified as traumatic or non-traumatic.

\section{Data collection}

Due to the nature of the research design, interventions will not be mandated as part of the study. Based on routine clinical practice, specified assessments will be conducted annually in patients aged $<18$ years and every 2 years in patients aged $\geq 18$ years (figure 2 ). A schedule of assessments showing the procedures and measurements taken for patients aged $<18$ and $\geq 18$ years (including those who receive treatment with burosumab, a new drug to be launched for the treatment of XLH) is shown in table 1. Patients aged $<18$ years will undergo measurements of sitting height, arm length and leg length, height and body weight, among other assessments. For patients aged $\geq 18$ years, data will be collected on the treatment received for the underlying disease and its complications, and bone mineral density, among other parameters. For patients aged $\geq 18$ years, bone mineral density will be measured by dual-energy X-ray absorptiometry (site of measurement: hip, lumbar spine, or other).

For patients who start the treatment with burosumab during the study, observation, examination and assessments will be performed before the start of treatment with burosumab, at 3 months, 6 months, 1 year and once a year thereafter for patients aged $<18$ years, and every 2 years for patients aged $\geq 18$ years. For patients who have received burosumab before participation in the study, data before the start of treatment with burosumab will be retrospectively collected. 

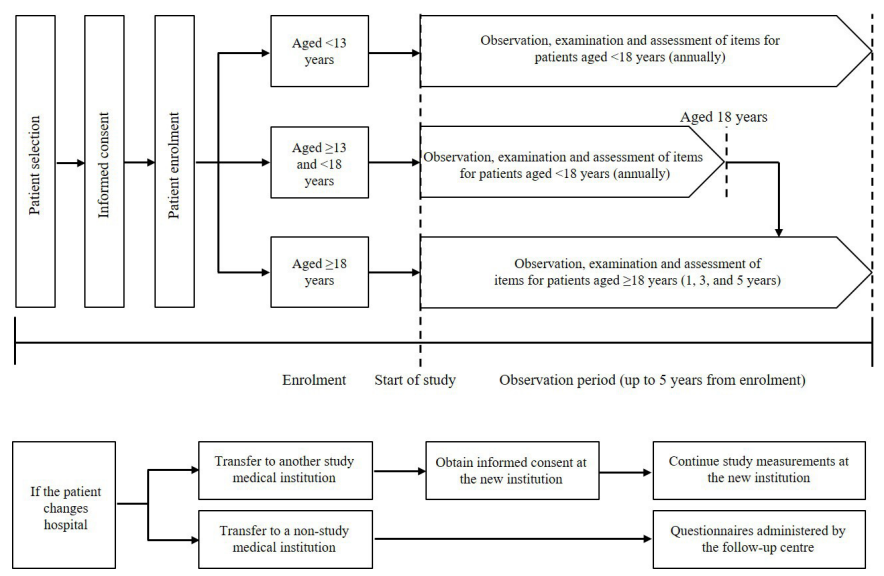

Figure 2 Schematic of study flow.

\section{Assessments}

Observation, examination and assessment items include demographic and baseline characteristics, radiographs (images of wrists, knees and leg long bones), ultrasonograms, dental assessment, surgical or medication requirements for the underlying disease, disease-related complications, laboratory tests, motor function $(\geq 5$ years to $<18$ years: 6 -min walk test $(6 \mathrm{MWT}),{ }^{32} \geq 18$ years: timed up and go test (TUGT) ${ }^{33}$ and grip strength), loss of working/learning opportunities and serious adverse events. Safety in terms of renal function will also be evaluated by serum and urine analysis and renal ultrasonography; however, as this is an observational study, management of safety events will not be performed by the study investigators. Adverse events will be managed by the treating physician according to their judgement. Retrospective data will also be collected for some parameters, including height, body weight, Tanner stage (patients aged $<18$ years), previous treatment and history of active fractures (including pseudofractures).

\section{Disease-related and treatment-related complications}

The date of onset for the following disease-related complications will be collected: femoral curvature, tibial/fibular curvature, genu varum, pigeon-toed gait, genu valgum, abnormal gait/running, leg length discrepancy, coxa vara, spinal canal stenosis, renal calculus, nephrocalcinosis, hypertension, chronic kidney disease (stage 3-5), haemodialysis, Chiari malformation, syringomyelia, increased intracranial pressure, deafness, tinnitus, dizziness, hypercalciuria, hypercalcaemia, hyperparathyroidism and others. For bone pain, arthralgia, osteoarthritis, joint stiffness, osteophyte formation, enthesopathy, spinal canal stenosis, ossification of posterior longitudinal ligament, ossification of anterior longitudinal ligament and ossification of yellow ligament, in addition to the date of onset, the site of onset will also be collected.

\section{Laboratory assessments}

Blood and urine sampling will be performed at least 4 hours after a meal or intake of a phosphate preparation.
Blood chemistry evaluations will include FGF23, phosphate, calcium, albumin, intact parathyroid hormone, 1,25-dihydroxyvitamin $\mathrm{D}$, 25-hydroxyvitamin $\mathrm{D}$, alkaline phosphatase, bone-specific alkaline phosphatase, creatinine and blood urea nitrogen. Urinalysis will be performed to evaluate phosphate, calcium, albumin and creatinine levels.

\section{Functional assessments}

As leg length may be a potential predictor of future height, ${ }^{24}$ annual anthropometric measurements (height, leg length, arm length and sitting height to a maximum extent) performed in patients aged $<18$ years (during the growth stage) will be used to investigate the efficacy of XLH treatment during the long-term observation period.

In addition to the skeletal defects occurring in patients with XLH, dental health is also affected due to defective mineralisation, ${ }^{34}$ commonly resulting in dental defects, abscesses and periodontitis. ${ }^{55}$ Study assessments will, therefore, include presence or absence of disease manifestations such as dental caries, dental abscess, gingivitis and permanent tooth extraction, along with the number of affected teeth if there are sufficient evaluable data available.

Patients often have compromised ambulatory ability and impaired handgrip strength, among other functional problems. ${ }^{5636}$ Changes in walking ability over time will be assessed using the 6MWT and the TUGT, which provide means to measure functional exercise capacity in children and adults, respectively. ${ }^{33}{ }^{37}$ Handgrip strength (both hands in a sitting position), which is also associated with mobility and physical functioning, ${ }^{38}$ will also be evaluated.

\section{Q0L assessment}

QOL and economic burden (impact on ability to work/ learn) will be assessed using questionnaire-based patientreported outcome (PRO) measures, including a PRO measurement information system (all ages), ${ }^{39} 10$-item short-form health survey for children $(<18$ years $),{ }^{40}$ revised faces pain scale $(<18$ years $),{ }^{41}$ EuroQol 5-dimensions survey ( $\geq 8$ years), ${ }^{42}$ Western Ontario and McMaster Universities osteoarthritis index $(\geq 18 \text { years })^{43}$ and brief pain inventory ( $\geq 18$ years). ${ }^{44}$ PRO data concerning working/learning will be collected annually in patients aged $<18$ years and every 2 years for patients aged $\geq 18$ years, and a specifically prepared assessment sheet will be used for patients who are elementary school-aged children or older.

\section{Statistical analyses}

Study data will be analysed in an exploratory manner appropriate to an observational study. Categorical variables will be described by frequency and proportion; summary statistics (number of patients, mean, SD, minimum, median and maximum) will be used to report continuous data. Details of all analyses will be specified in the Statistical Analysis Plan (SAP) prepared prior to 


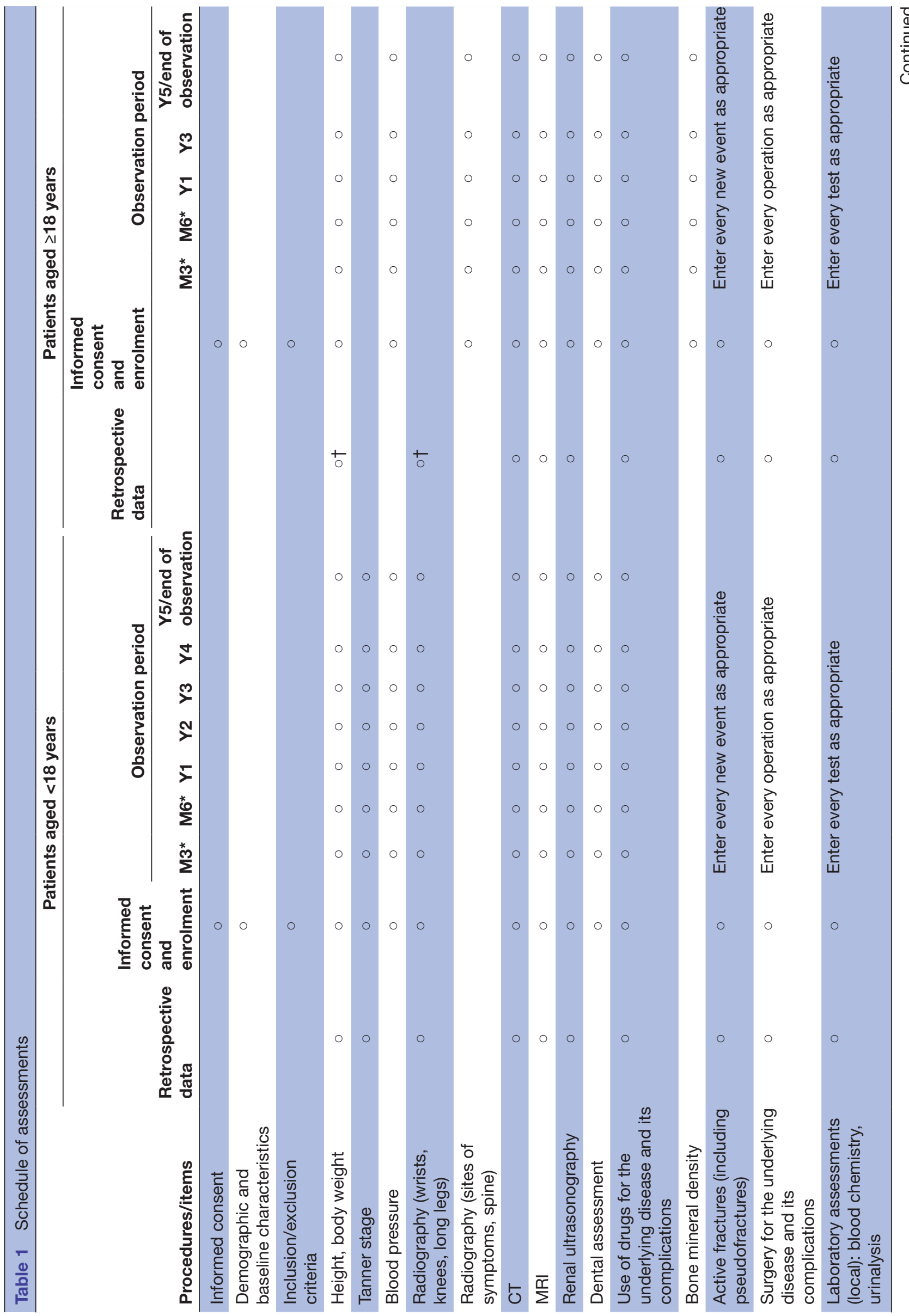

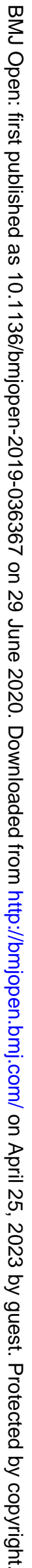




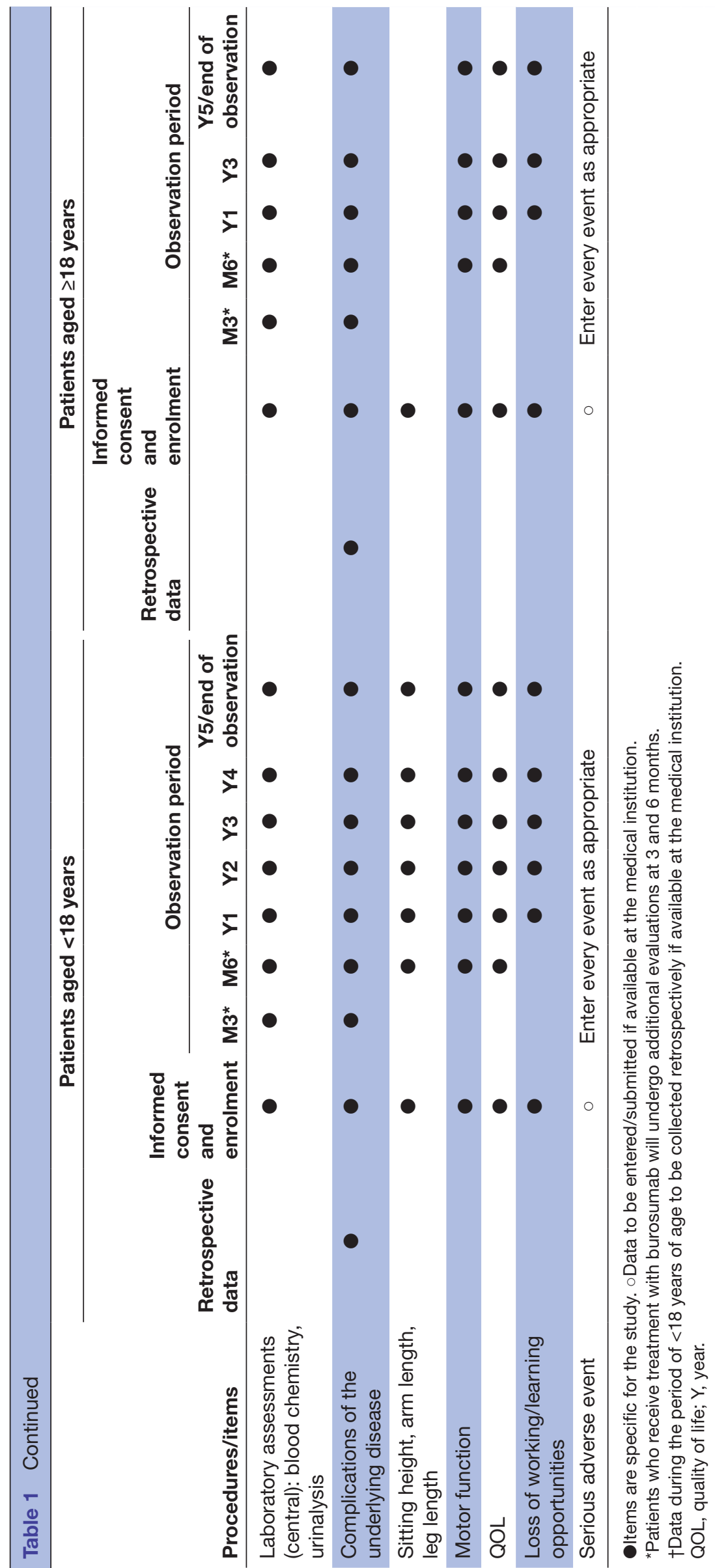

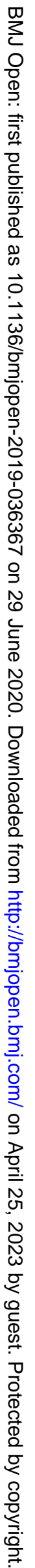


each analysis time point, including how missing data will be handled, and all analyses will be performed in accordance with the SAP.

\section{Patient and public involvement}

In contrast with the situation in western countries, there are no patient advocacy groups for XLH patients in the countries where this study is being conducted. As such, patient participation was not realised during the research planning stage of this study. However, the medical professionals (coauthors) who contributed to the development of the research plan have extensive clinical experience on this disease. Based on the information collected during real-world treatment of patients with XLH, the research plan was conceived with utmost consideration for XLH patients who will be enrolled this study.

\section{ETHICS AND DISSEMINATION}

\section{Data collection and dissemination}

Patients who give written informed consent for participation in the study will be registered using an electronic data capture (EDC) system. Data collected during the study will be entered into the EDC. Study investigators will be responsible for data input and correction of data.

Two interim analyses are planned using retrospective and enrolment data at year 1 (data lock in December 2019), and results at year 3 (data lock in December 2021). The Principal Investigator, the Steering Committee and Kyowa Kirin Co will make all decisions about the publication of the study data. The organisation of the study is detailed in online supplementary appendix 1 . The funding source has no role in the analyses and interpretation of data to be published.

\author{
Author affiliations \\ ${ }^{1}$ Department of Pediatrics, Graduate School of Medicine, Osaka University, Suita, \\ Japan \\ ${ }^{2}$ Fujii Memorial Institute of Medical Sciences, Institute of Advanced Medical \\ Sciences, Tokushima University, Tokushima, Japan \\ ${ }^{3}$ Department of Pediatric Nephrology, Seoul National University Children's Hospital, \\ Seoul, Republic of Korea \\ ${ }^{4}$ Department of Bone and Mineral Research, Osaka Women's and Children's \\ Hospital, Izumi, Japan \\ ${ }^{5}$ Department of Pediatrics and Perinatology, Faculty of Medicine, Tottori University, \\ Tottori, Japan \\ ${ }^{6}$ Division of Nephrology and Endocrinology, The University of Tokyo Hospital, Tokyo, \\ Japan \\ ${ }^{7}$ Medical Affairs Department, Kyowa Kirin Co Ltd, Tokyo, Japan
}

Acknowledgements We extend our thanks to the personnel at the medical institutions involved in the study for supporting data collection, and to all participants and their families for providing information. We also thank Hisatomi Arima (Department of Preventive Medicine and Public Health, Faculty of Medicine, Fukuoka University) and Ayumi Shintani (Department of Medical Statistics, Graduate School of Medicine, Osaka City University) for reviewing the study protocol and the manuscript, Sally-Anne Mitchell, PhD (Edanz Medical Writing) for providing medical writing support which was funded by Kyowa Kirin Co, and the Kyowa Kirin SUNFLOWER-study office for editorial support.

Contributors TK, ST and YG contributed to manuscript development. SF, HIC, TM, $\mathrm{NN}, \mathrm{NI}, \mathrm{TK}$ and $\mathrm{KO}$ contributed to study design, reviewed the manuscript critically and gave final approval for submission.
Funding This study was sponsored by Kyowa Kirin Co. Kyowa Kirin Co will participate in supporting decisions about the study in consultation with the lead principal investigator, but will not be involved in analyses and interpretation of data to be published. Kyowa Kirin $\mathrm{Co}$ is the manufacturer and distributor of burosumab.

Competing interests TK has received personal fees from Kyowa Kirin Co for the submitted work and grants from Kyowa Kirin Co outside the submitted work. SF has received grants from Teijin Pharma and Astellas Pharma; and held an endowed chair position with Chugai Pharmaceutical $\mathrm{Co}$, Ono Pharmaceutical $\mathrm{Co}$, Taisho Pharmaceutical Co and Kyowa Kirin Co outside the submitted work. TM has received personal fees (honorarium) from Kyowa Kirin Co for serving as a member of the advisory board during the conduct of this study. NN has received personal fees from Kyowa Kirin Co for the submitted work; and grants from Kyowa Kirin Co outside the submitted work. NI has received research grants from Kyowa Kirin Co outside the submitted work. ST and YG are the employees of Kyowa Kirin Co. KO has received lecture fees from Kyowa Kirin Co, Alexion Pharmaceuticals and Novo Nordisk Pharma outside the submitted work.

Patient consent for publication Not required.

Provenance and peer review Not commissioned; externally peer reviewed.

Open access This is an open access article distributed in accordance with the Creative Commons Attribution Non Commercial (CC BY-NC 4.0) license, which permits others to distribute, remix, adapt, build upon this work non-commercially, and license their derivative works on different terms, provided the original work is properly cited, appropriate credit is given, any changes made indicated, and the use is non-commercial. See: http://creativecommons.org/licenses/by-nc/4.0/.

\section{ORCID iD}

Takuo Kubota http://orcid.org/0000-0003-4483-4405

\section{REFERENCES}

1 Endo I, Fukumoto S, Ozono K, et al. Nationwide survey of fibroblast growth factor 23 (FGF23)-related hypophosphatemic diseases in Japan: prevalence, biochemical data and treatment. Endocr $J$ 2015;62:811-6.

2 Beck-Nielsen SS, Brock-Jacobsen B, Gram J, et al. Incidence and prevalence of nutritional and hereditary rickets in southern Denmark. Eur J Endocrinol 2009;160:491-7.

3 Burnett CH, Dent CE, Harper C, et al. Vitamin D-resistant rickets. Analysis of twenty-four pedigrees with hereditary and sporadic cases. Am J Med 1964;36:222-32.

4 Dixon PH, Christie PT, Wooding C, et al. Mutational analysis of PHEX gene in X-linked hypophosphatemia. J Clin Endocrinol Metab 1998;83:3615-23.

5 Carpenter TO, Imel EA, Holm IA, et al. A clinician's guide to X-linked hypophosphatemia. J Bone Miner Res 2011;26:1381-8.

6 Beck-Nielsen SS, Mughal Z, Haffner D, et al. Fgf23 and its role in X-linked hypophosphatemia-related morbidity. Orphanet J Rare Dis 2019;14:58.

7 Rowe PS, Goulding JN, Francis F, Summerfield T, et al. The gene for X-linked hypophosphataemic rickets maps to a 200-300kb region in Xp22.1, and is located on a single YAC containing a putative vitamin D response element (VDRE). Hum Genet 1996;97:345-52.

8 Sabbagh Y, Jones AO, Tenenhouse HS. PHEXdb, a locus-specific database for mutations causing X-linked hypophosphatemia. Hum Mutat 2000;16:1-6.

9 Bitzan M, Goodyer PR. Hypophosphatemic rickets. Pediatr Clin North Am 2019;66:179-207.

10 Acar S, Demir K, Shi Y. Genetic causes of rickets. J Clin Res Pediatr Endocrinol 2017;9:88-105.

11 Yamazaki Y, Okazaki R, Shibata M, et al. Increased circulatory level of biologically active full-length FGF-23 in patients with hypophosphatemic rickets/osteomalacia. J Clin Endocrinol Metab 2002;87:4957-60.

12 Jonsson KB, Zahradnik R, Larsson T, et al. Fibroblast growth factor 23 in oncogenic osteomalacia and X-linked hypophosphatemia. $N$ Engl J Med 2003;348:1656-63.

13 Rowe PSN. Regulation of bone-renal mineral and energy metabolism: the PHEX, FGF23, DMP1, MEPE ASARM pathway. Crit Rev Eukaryot Gene Expr 2012;22:61-86.

14 Skrinar A, Dvorak-Ewell M, Evins A, et al. The lifelong impact of Xlinked hypophosphatemia: results from a burden of disease survey. $J$ Endocr Soc 2019;3:1321-34.

15 Linglart A, Biosse-Duplan M, Briot K, et al. Therapeutic management of hypophosphatemic rickets from infancy to adulthood. Endocr Connect 2014;3:R13-30. 
16 Tenenhouse HS, Econs MJ. Mendelian hypophosphatemias. In: Scriver CR, Beaudet AL, Sly WS, et al, eds. The metabolic and molecular basis of inherited disease. 8 edn. New York: McGraw Hill, 2000: 5039-67.

17 Che $\mathrm{H}$, Roux $\mathrm{C}$, Etcheto $\mathrm{A}$, et al. Impaired quality of life in adults with $\mathrm{X}$-linked hypophosphatemia and skeletal symptoms. Eur J Endocrinol 2016;174:325-33.

18 Chesher D, Oddy M, Darbar U, et al. Outcome of adult patients with X-linked hypophosphatemia caused by PHEX gene mutations. J Inherit Metab Dis 2018;41:865-76.

19 Watts L, Wordsworth P, malformation C. Chiari malformation, syringomyelia and bulbar palsy in $\mathrm{X}$ linked hypophosphataemia. BMJ Case Rep 2015;2015. doi:10.1136/bcr-2015-211961. [Epub ahead of print: 11 Nov 2015].

20 Vakharia JD, Matlock K, Taylor HO, et al. Craniosynostosis as the presenting feature of $\mathrm{X}$-linked hypophosphatemic rickets. Pediatrics 2018;141:S515-9.

21 Rothenbuhler A, Fadel N, Debza Y, et al. High incidence of cranial synostosis and chiari I malformation in children with X-linked hypophosphatemic rickets (XLHR). J Bone Miner Res 2019;34:490-6.

22 Rothenbuhler A, Schnabel D, Högler W, et al. Diagnosis, treatmentmonitoring and follow-up of children and adolescents with X-linked hypophosphatemia (XLH). Metabolism 2020;103S:153892.

23 Santos F, Fuente R, Mejia N, et al. Hypophosphatemia and growth. Pediatr Nephrol 2013;28:595-603.

24 Zivičnjak M, Schnabel D, Billing $\mathrm{H}$, et al. Age-related stature and linear body segments in children with X-linked hypophosphatemic rickets. Pediatr Nephrol 2011;26:223-31.

25 Connor J, Olear EA, Insogna KL, et al. Conventional therapy in adults with X-linked hypophosphatemia: effects on enthesopathy and dental disease. J Clin Endocrinol Metab 2015;100:3625-32.

26 Quinlan C, Guegan K, Offiah A, et al. Growth in PHEX-associated Xlinked hypophosphatemic rickets: the importance of early treatment. Pediatr Nephrol 2012;27:581-8.

27 Fukumoto S, Ozono K, Michigami T, et al. Pathogenesis and diagnostic criteria for rickets and osteomalacia - proposal by an expert panel supported by ministry of health, labour and welfare, Japan, the Japanese society for bone and mineral research and the Japan endocrine society [Opinion]. Endocr J 2015;62:665-71.

28 Haffner D, Emma F, Eastwood DM, et al. Clinical practice recommendations for the diagnosis and management of $X$-linked hypophosphataemia. Nat Rev Nephrol 2019;15:435-55.

29 Endo I, Fukumoto S, Ozono K, et al. Clinical usefulness of measurement of fibroblast growth factor 23 (FGF23) in hypophosphatemic patients: proposal of diagnostic criteria using FGF23 measurement. Bone 2008;42:1235-9.
30 Fukumoto S, Ozono K, Michigami T, et al. Pathogenesis and diagnostic criteria for rickets and osteomalacia--proposal by an expert panel supported by the ministry of health, labour and welfare, Japan, the Japanese Society for bone and mineral research, and the Japan endocrine Society. J Bone Miner Metab 2015;33:467-73.

31 Thacher TD, Pettifor JM, Tebben PJ, et al. Rickets severity predicts clinical outcomes in children with X-linked hypophosphatemia: utility of the radiographic rickets severity score. Bone 2019;122:76-81.

32 Butland RJ, Pang J, Gross ER, et al. Two-, six-, and 12-minute walking tests in respiratory disease. Br Med J 1982;284:1607-8.

33 Podsiadlo D, Richardson S. The timed "Up \& Go": a test of basic functional mobility for frail elderly persons. J Am Geriatr Soc 1991;39:142-8.

34 Coyac BR, Hoac B, Chafey P, et al. Defective mineralization in X-linked hypophosphatemia dental pulp cell cultures. J Dent Res 2018;97:184-91.

35 Lee B-N, Jung $\mathrm{H}-\mathrm{Y}$, Chang $\mathrm{H}-\mathrm{S}$, et al. Dental management of patients with X-linked hypophosphatemia. Restor Dent Endod 2017;42:146-51.

36 Lambert A-S, Zhukouskaya V, Rothenbuhler A, et al. X-linked hypophosphatemia: management and treatment prospects. Joint Bone Spine 2019;86:731-8.

37 Geiger R, Strasak A, Treml B, et al. Six-minute walk test in children and adolescents. J Pediatr 2007;150:395-9.

38 Jakobsen LH, Rask IK, Kondrup J. Validation of handgrip strength and endurance as a measure of physical function and quality of life in healthy subjects and patients. Nutrition 2010;26:542-50.

39 Cella D, Riley W, Stone A, et al. The patient-reported outcomes measurement information system (PROMIS) developed and tested its first wave of adult self-reported health outcome item banks: 2005 2008. J Clin Epidemiol 2010;63:1179-94.

40 Saris-Baglama RN, DeRosa MA, Raczek AE, et al. Development, validation, and norming of the SF-10 for children health survey (abstract). Qual Life Res 2006;15:A-145.

41 Hicks CL, von Baeyer CL, Spafford PA, et al. The faces pain scalerevised: toward a common metric in pediatric pain measurement. Pain 2001:93:173-83.

42 Rabin R, de Charro F. EQ-5D: a measure of health status from the EuroQol group. Ann Med 2001;33:337-43.

43 Bellamy N, Buchanan WW, Goldsmith $\mathrm{CH}$, et al. Validation study of WOMAC: a health status instrument for measuring clinically important patient relevant outcomes to antirheumatic drug therapy in patients with osteoarthritis of the hip or knee. J Rheumatol 1988;15:1833-40.

44 Daut RL, Cleeland CS, Flanery RC. Development of the wisconsin brief pain questionnaire to assess pain in cancer and other diseases. Pain 1983;17:197-210. 